\title{
NATM TUNNELS - CONSIDERATION OF THE PARTLY DAMAGED PRIMARY LINING IMPACT FOR THE SECONDARY LINING EVALUATION
}

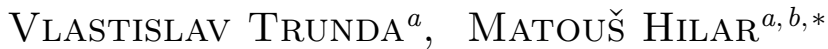 \\ ${ }^{a}$ Czech Technical University in Prague, Faculty of Civil Engineering, Department of Geotechnics, Thákurova \\ 2077/7, 16629 Prague 6, Czech Republic \\ ${ }^{b} 3 G$ Consulting Engineers s.r.o. Na Usedlosti 16, 14700 Prague, Czech Republic \\ * corresponding author: hilar@3-g.cz
}

\begin{abstract}
Tunnels excavated by the New Austrian Tunnelling Method (NATM) are traditionally supported by a double-shell lining. The primary lining is generated from reinforced sprayed concrete with rockbolts, the secondary lining is generated from in-situ cast concrete and it is protected by a waterproof membrane. The static evaluation of the long term behaviour generally assumes full degradation of the primary lining (the primary lining impact is not considered). Some investigations of tunnels constructed in past indicated that the primary lining degradation is slower than expected. This paper discusses possibilities of partly damaged primary lining consideration in static calculations of the secondary lining. Various options were verified by numerical modelling, and its results were compared and discussed.
\end{abstract}

KEYWORDS: NATM, primary lining, numerical calculations, durability, lifetime.

\section{INTRODUCTION}

Tunnels excavated by the New Austrian Tunnelling Method (NATM) are traditionally supported by double-shell lining [1]. The primary lining is generated from reinforced sprayed concrete with rockbolts, the secondary lining is generated from in-situ cast concrete and it is protected by a waterproof membrane 2 . The primary lining is in contact with the surrounding ground and underground water, the primary lining lifetime (durability) can be significantly reduced by its contact with adjacent environment (decomposition of sprayed concrete, corrosion of steel rockbolts and reinforcement, etc.). The full degradation of the primary lining is normally considered during the secondary lining design and evaluation [1, 2, this approach is assumed to be reasonably conservative.

The use of spray-applied waterproofing membranes [3, 4] is an associated topic, as it offers to use the primary lining for a permanent purpose. Traditionally, waterproofing of a tunnel lining is provided by means of a prefabricated sheet membrane, but it can be replaced by a sprayed waterproofing membrane applied on site. The spray-applied waterproofing membranes bond to the substrate and structurally connect the primary and the secondary lining, resulting in the so-called composite lining, which can also bring a lining thickness reduction due to the primary lining contribution.

Some recent researches indicate that the primary lining degradation is significantly slower than expected [5. It would indicate a possibility to consider partly decomposed primary lining for the secondary lining evaluation. Further details are discussed in this paper.

\section{TUNNEL LINING DESIGN BASED ON NATM PRINCIPLES}

Requirements on the primary tunnel lining and the secondary tunnel lining are different, as roles of these two layers are not the same.

\subsection{Primary Lining Design}

The primary lining is generally installed instantly after an excavation of particular advance (Fig. 1). The primary lining should be flexible (according to the NATM principles) to allow ground deformations, which can be beneficial for a redistribution of ground stresses. Relationship of pressures and deformation generally follows Fenner-Pacher curve.

The primary lining is generally loaded by:

- Ground pressures

- Tunnel lining weight

\subsection{SECONDARY LINING DESIGN}

The secondary lining is generally installed after a stabilisation of ground deformations (Fig. 2). Therefore, the secondary lining is not initially loaded by ground pressure, which was confirmed by various measurements in past.

The secondary lining is generally loaded by:

- Ground pressures

- Tunnel lining weight

- Hydrostatic pressure 


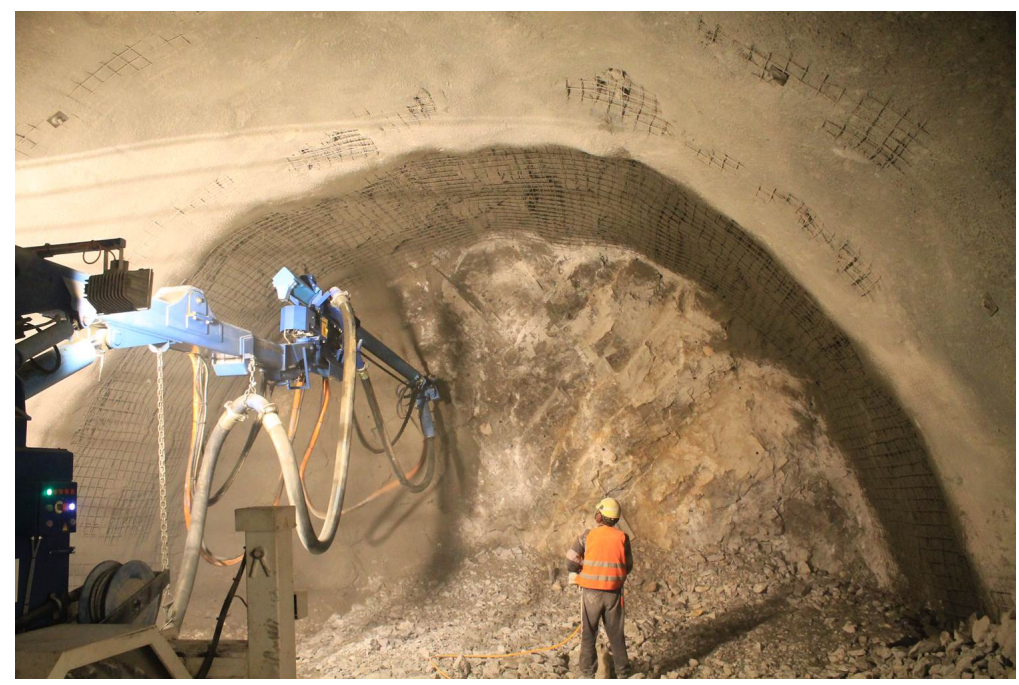

FIGURE 1. The primary lining construction from sprayed concrete (photo Hilar).

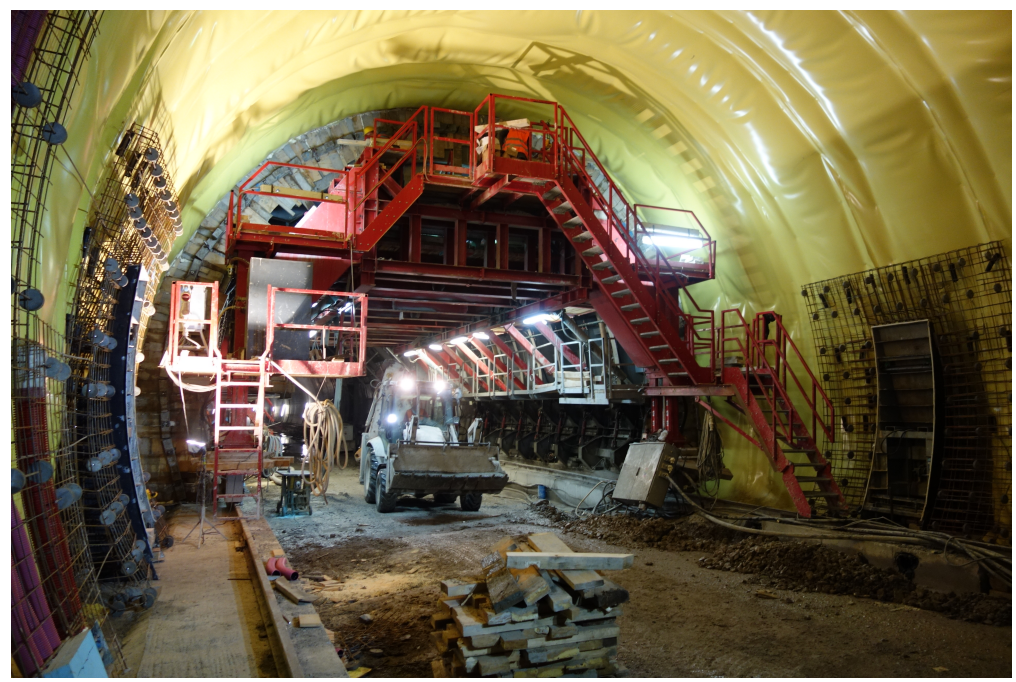

Figure 2. The secondary lining construction from in situ cast concrete (photo Hilar).

- Temperature variation

- Concrete shrinkage and creep

- Operational loads (weight of technologies, collisions, etc.)

\section{Primary lining Degradation}

Primary lining degradation is generally accepted process, which, so far, has not been investigated in detail, because the primary lining is not accessible after the secondary lining installation. Designers only assume that the primary lining can be damaged during a tunnel lifetime and thus the primary lining is not considered during the secondary lining evaluation. The primary lining lifetime (durability) depends on its properties and surrounding conditions.

The following factors can negatively affect the primary lining lifetime (durability):

- Ground properties

- Ground water presence and properties
- Ground gas presence and properties

- Organic particles in ground

- Dynamic load

- Electric currents in ground

\subsection{Corrosion of Rockbolts}

Similarly to the primary lining, an evaluation of the lifetime (durability) of rockbolts (Fig. 3) is also complicated due to its problematic accessibility after the secondary lining installation. But some case studies of degradation of rockbolts and ground anchors used for portals and retaining walls are available in professional literature. Degradation is usually caused by a combination of various impacts, including problematic compliance with requirements for manufacturing, transport, storage and installation. A corrosion of rockbolts can be fully eliminated by usage of fibreglass rockbolts which have some further benefits (lower deformations, lower weight, better manipulation, etc.). 


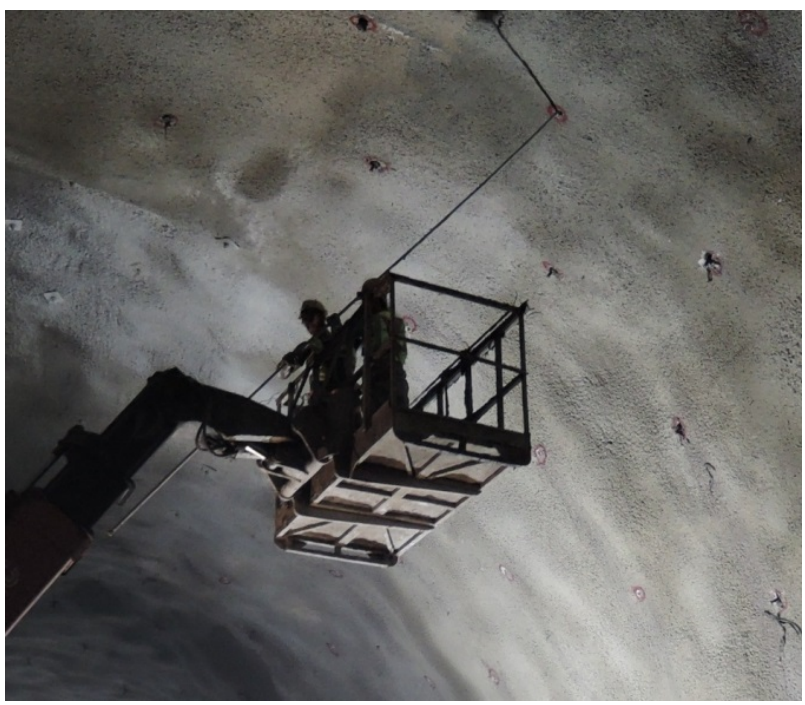

FiguRE 3. Installation of rockbolts (photo Hilar).

Major disadvantages are higher cost and fragile behaviour.

\subsection{Concrete DEgradation}

NATM assumes a direct contact of primary lining generated from sprayed concrete with the surrounding ground. Therefore, the sprayed concrete is affected by various impacts, which can reduce its lifetime and durability.

Pfiffner and Holzer [6] investigated concrete degradation in three Swiss tunnels and highlighted the occurrence of two most common processes of degradation, which are mutually overlapping. These two processes are more or less independent on the degree of aggressiveness of the surrounding ground and on underground water. The degradation is associated with a disruption of cement stone and sulphate attack. In the first case, particles from cement stone are disturbed, dissolved and washed out. In the second case, an interaction with ground water containing sulphates can lead to a chemical and mineralogical change of cement stone leading to a creation of new minerals as gypsum, etringit or thaumasit. This process is associated with a concrete volume increment, which can lead to cracks, softening and strength reduction.

\subsection{LONG-TERM GROUND BEHAVIOUR}

The primary lining degradation can also be affected by an additional ground load, which can be caused by a long-term ground behaviour. The following aspects can have an impact:

- consolidation

- swelling

- landslides

\section{Partial Degradation of PRIMARY LINING MODELLING}

The finite element method or finite difference method are usually used for a numerical modelling of underground structures. These methods can also be used for a numerical modelling of a partly degraded primary lining.

The degradation process can be modelled using a so called "grey rock philosophy". This approach assumes that the degraded primary lining can be modelled as a part of ground simulated with lower shear parameters and lower bending capacity (i.e. material without tension capacity).

Hurt [7] describes that the degraded primary lining consideration significantly reduced the cost of the project "The Channel Tunnel Rail Link: North Downs Tunnel". The grey rock theory was only considered for sections with low overburden, where traditional secondary lining did not have a sufficient capacity and had to be additionally reinforced. The following input parameters were applied for the degraded primary lining:

- $E=10 \mathrm{GPa}$

- $c=0 \mathrm{kPa}$

- $\varphi=30^{\circ}$

Marcher and Jiřičný [8] recommend an increment of parameters of the degraded primary lining to gain a better stability of numerical calculations. The realised parametric study proved that increased parameters have a small impact on the secondary lining load. The following input parameters were applied for the degraded primary lining:

- $E=10 \mathrm{GPa}$

- $c=40 \mathrm{kPa}$

- $\varphi=40^{\circ}$

Also, Thomas 11, considered the partly degraded primary lining in his investigation, he assumes a $50 \%$ degradation of the primary lining. The following input parameters were applied for the degraded primary lining in his studies:

- $E=10 \mathrm{GPa}$

- $c=2.000 \mathrm{kPa}$

- $\varphi=45^{\circ}$

\section{Numerical MODELLING}

Numerical calculations were realised to verify possibilities of a partly degraded primary lining modelling. The models were prepared in $2 \mathrm{D}$, basic recommendations for numerical modelling of underground structures were respected (Fig. 4). Stress relief was used to simulate the stress redistribution in the tunnel face area 9 . The following calculations were realised for a uniform overburden of $23 \mathrm{~m}$ :

- Circular tunnel profile (full face excavation) 


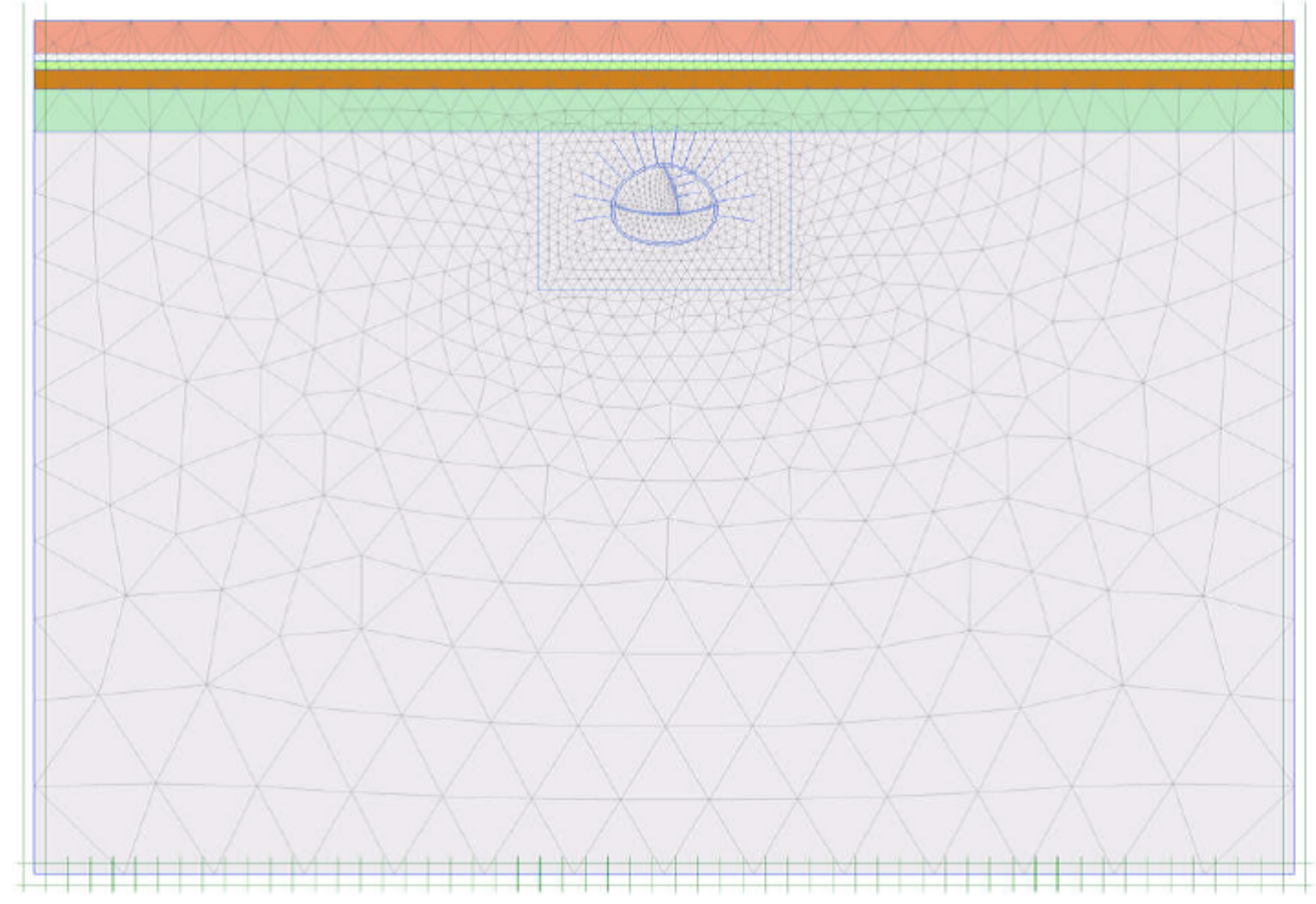

FiguRE 4. Finite element mesh with horizontal tunnel face sequencing.

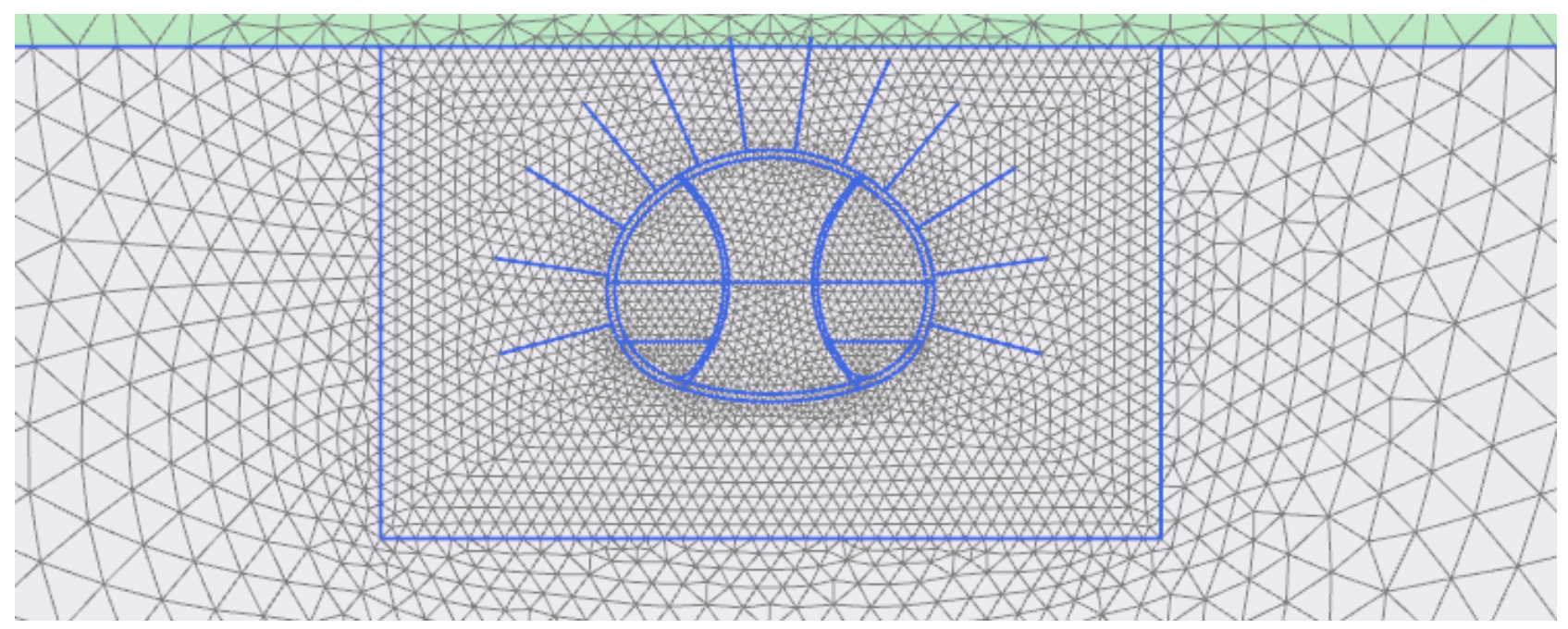

Figure 5. Detail of finite element mesh with vertical tunnel face sequencing.

\begin{tabular}{lcccccc}
\hline Layer & $\begin{array}{c}\gamma \\
{[\mathrm{kN} / \mathrm{m} 3]}\end{array}$ & $\begin{array}{c}E \\
{[\mathrm{MPa}]}\end{array}$ & $\begin{array}{c}c \\
{[\mathrm{kPa}]}\end{array}$ & $\begin{array}{c}\varphi \\
{\left[{ }^{\circ}\right]}\end{array}$ & $\begin{array}{c}v \\
{[-]}\end{array}$ & $\begin{array}{c}K_{0} \\
{[-]}\end{array}$ \\
\hline AN - made-up ground & 20.5 & 11 & 13 & 24 & 0.37 & 0.59 \\
E - eolian sediments & 19.5 & 10 & 25 & 22 & 0.39 & 0.63 \\
W5 - very weathered shale & 21.0 & 30 & 15 & 30 & 0.33 & 0.50 \\
W4-W3 - partly weathered shale & 22.5 & 90 & 25 & 30 & 0.31 & 0.50 \\
W2 - slightly weathered shale & 24.5 & 220 & 50 & 32 & 0.25 & 0.47 \\
W1 - unweathered shale & 25.8 & 300 & 125 & 37 & 0.25 & 0.40 \\
\hline
\end{tabular}

TABLE 1. Geotechnical input parameters applied for modelling. 


\begin{tabular}{lcccccc}
\hline \multirow{2}{*}{ Tunnel profile } & \multicolumn{2}{c}{ Without degradation } & \multicolumn{2}{c}{ Thomas [1] } & \multicolumn{2}{c}{ Marcher and Jiřičný [ $]$} \\
\cline { 2 - 7 } & $N[\mathrm{kN}]$ & $M[\mathrm{kNm}]$ & $N[\mathrm{kN}]$ & $M[\mathrm{kNm}]$ & $N[\mathrm{kN}]$ & $M[\mathrm{kNm}]$ \\
\hline Circle - full face & -27 & 10 & -56 & 58 & -839 & 89 \\
Horizontal sequencing & -28 & 11 & -57 & 65 & -1015 & 273 \\
Vertical sequencing & -308 & 11 & -515 & 125 & -1616 & 366 \\
\hline
\end{tabular}

TABLE 2. Values of internal forces in the secondary lining.

\begin{tabular}{lccc}
\hline \multirow{2}{*}{ Tunnel profile } & Without degradation & Thomas [1] & Marcher and Jiřičný $[8]$ \\
\cline { 2 - 4 } & $A_{s, 1}\left[\mathrm{~cm}^{2}\right]$ & $A_{s, 1}\left[\mathrm{~cm}^{2}\right]$ & $A_{s, 1}\left[\mathrm{~cm}^{2}\right]$ \\
\hline Circle - full face & $0.0 \Rightarrow 5.7$ & $4.8 \Rightarrow 5.7$ & $0.0 \Rightarrow 5.7$ \\
Horizontal sequencing & $0.0 \Rightarrow 5.7$ & $5.5 \Rightarrow 5.7$ & 19.5 \\
Vertical sequencing & $0.0 \Rightarrow 5.7$ & $5.2 \Rightarrow 5.7$ & 27.8 \\
\hline
\end{tabular}

TABLE 3. Areas of the secondary lining reinforcement according EN 1992-1-1.

- Elliptical tunnel profile (horizontal tunnel face sequencing) - Fig. 4

- Elliptical tunnel profile (vertical tunnel face sequencing) - Fig. 5

The ground was modelled using 15 node triangular elements. Mohr-Coulomb material model was used to simulate the ground behaviour. Geotechnical input parameters are summarised in Tab. 1] layers are listed from the surface (marked AN) to the layer surrounding the tunnel profile (marked W1).

15 node triangular elements were also used for the primary lining modelling, where a linear-elastic material model was applied. The realised modelling took into consideration the age of the primary lining from sprayed concrete and its development in time. The secondary lining from in situ cast reinforced concrete was modelled using beam elements with a relevant bending capacity. The degraded primary lining was also modelled using 15 node triangular elements with the following input parameters:

- Input parameters according Thomas [1]

- Input parameters according Marcher and Jiřičný [8]

A generated finite element mesh for an elliptical tunnel shape with a vertical tunnel face sequencing is presented in Fig. 4 The primary lining was modelled by triangular elements. Rockbolts were modelled using beam elements called "geogrid", which resist to tension (linear behaviour), but do not resist to compression or bending. Input parameters of rockbolts (elastic modulus $E$, area $A$, and capacity in tension $N$ ) corresponded with the installed self-drilling rockbolts IBO 51. A full degradation of rockbolts was assumed in the realised calculations.

\section{RESUlts AND DISCUSSION}

Presented variation of input parameters was used for each modelled tunnel profile. Values of internal forces (normal forces and bending moments) in the secondary lining were investigated for each calculation.
Internal forces in the secondary lining with undamaged (original) primary lining were used as a reference. Results are presented in Tab. 2 .

Results of realised calculations show that the resulting internal forces in the secondary lining are significantly affected by a degree of the primary lining degradation (i.e. there is a correlation between resulting internal forces and shear parameters of the primary lining).

All calculations also include cases, where the primary lining was replaced by ground (i.e. assumed full degradation of the primary lining). Values of internal forces in the secondary lining were similar to the cases with primary lining parameters derived according Marcher and Jiřičný [8. This output was partly affected by $E$ modulus of the degraded primary lining and partly by favourable shear parameters of the adjacent ground.

The secondary lining was considered to be $35 \mathrm{~cm}$ thick and generated from concrete $\mathrm{C} 30 / 37$, the secondary lining was evaluated according to EN 1992-1-1. The minimum area of the reinforcement $A_{s, \min }$ for the given secondary lining, according to EN 1992-1-1, was calculated as $5.7 \mathrm{~cm}^{2}$. Calculated areas of the reinforcement $A_{s}$ are presented in Tab. 3

\section{CONClusion}

The presented paper discusses possibilities of the primary lining partial degradation consideration for the secondary lining evaluation. The paper summarises actual information about the degradation of the primary lining from sprayed concrete including rockbolts. Then, various possibilities of partly damaged primary lining are presented and discussed. Consequently, 2D numerical modelling was performed to realise a parametric study.

Results of the realised calculations show that resulting internal forces in the secondary lining are affected by a degree of the primary lining degradation (i.e. there is a correlation between resulting internal forces 
and shear parameters of the primary lining). The results of the realised numerical calculations show that a consideration of the partly damaged primary lining can bring significant cost savings for the secondary lining design. The results comply with conclusions of some other authors [2, 5].

\section{ACKNOWLEDGEMENTS}

Financial support from the TAČR grant TE01020168 is gratefully acknowledged.

\section{REFERENCES}

[1] A. Thomas. Sprayed Concrete Lined Tunnels. CRC Press, London, 1st edn., 2008. DOI: $10.1201 / 9781482265682$

[2] A. Pickett, A. Thomas. Where are we now with sprayed concrete lining in tunnels? Tunnelling Journal Fall 2013.

[3] B. Pisova, M. Hilar. Spray-applied waterproofing membranes: effective solution for safe and durable tunnel linings? In IOP Conference Series: Materials Science and Engineering, vol. 236, p. 012087. IOP Publishing, 2017. DOI:10.1088/1757-899x/236/1/012087.

[4] J. Su, A. Blootworth. On composite action and tunnel lining design; is composite action beneficial in reducing lining thickness? Tunnelling Journal pp. 38 - 46, 2019.
[5] F. Vogel, R. Sovják, O. Holčapek, et al. Experimental study of primary lining tunnel concrete after thirty years of operation. In Applied Methods of the Analysis of Static and Dynamic Loads of Structures and Machines, vol. 732 of Applied Mechanics and Materials, pp. 403 - 406. Trans Tech Publications Ltd, 2015. DOI:10.4028/www.scientific.net/AMM.732.403

[6] M. Pfiffner, L. Holzer. Schädigungsmechanismen der Betonkorrosion in Tunnelbauwerken. Forschungsauftrag ASTRA 1999/145(53/99), 2002.

[7] J. Hurt. Primary ways to save. Tunnel \& Tunneling International 34(1), 2002.

[8] T. Marcher, F. Jiřičný. Zur Wechselwirkung der Spritzbetonaußenschale mit der später eingebauten Tunnelinnenschale unter Berücksichtigung relevanter Langzeiteffekte. In Bauen in Boden und Fels, 4. Kolloquium 20. und 21. Januar 2004. Ostfildern, 2004.

[9] S. Kielbassa, H. Duddeck. Stress-strain fields at the tunnelling face-Three-dimensional analysis for two-dimensional technical approach. Rock Mechanics and Rock Engineering 24:115 - 132, 1991. DOI:10.1007/BF01042857 